\title{
Prevalence of and risk factors for retinopathy of prematurity in a cohort of preterm infants treated exclusively with non-invasive ventilation in the first week after birth
}

\author{
S K van der Merwe, N Freeman, A Bekker, J Harvey, J Smith \\ Tygerberg Children's Hospital and Department of Paediatrics, Stellenbosch University, Parow, Cape Town \\ $\mathrm{S}$ K van der Merwe, MB ChB, DCH (SA), FCPaed (SA), Cert Neonatol (SA) \\ N Freeman, MB ChB, FCOphth (SA), MMed \\ A Bekker, MB ChB, DCH (SA), FCPaed (SA), MMed, Cert Neonatol (SA) \\ J Smith, MB ChB, MMed, FCPaed (SA), PhD \\ Faculty of Medicine and Health Sciences, Stellenbosch University, Parow, Cape Town \\ J Harvey, PhD (Mathematical Statistics)
}

Corresponding author: S K van der Merwe (rina1077@gmail.com)

\begin{abstract}
Objectives. To determine the current prevalence of retinopathy of prematurity (ROP) in premature babies treated with non-invasive ventilation at Tygerberg Children's Hospital, Parow, Cape Town, South Africa, and to identify risk factors associated with the development of ROP.

Methods. A retrospective medical records review of infants screened for ROP during a 2-year period (January 2009 - December 2010). Infants who did not receive invasive ventilation during the first week of life were included. Twenty-four previously reported risk factors for the development of ROP were identified for use in a multivariate logistic regression (MLR) analysis.

Results. A total of 356 patients were included. The overall prevalence of ROP was $21.8 \%$ and that of clinically significant ROP (CSROP) $4.4 \%$. The risk factors with a statistically significant association with the development of ROP on MLR analysis were severe apnoea ( $p=0.0005)$ and decreasing birth weight $(p=0.0382)$.

Conclusions. There is a low prevalence of ROP in the cohort of preterm infants treated exclusively with non-invasive ventilation in the first week of life. The risk factors of importance in our population were severe apnoea and lower birth weight. Birth weight is a practical and reproducible variable that can be used to aid development of ROP screening criteria.
\end{abstract}

S Afr Med J 2013;103(2):96-101. DOI:10.7196/SAMJ.6131

Retinopathy of prematurity (ROP) is a serious disease of premature infants that can lead to blindness. In 1995 it accounted for $10.6 \%$ of blindness in children in schools for the blind in South Africa. ${ }^{1}$ ROP is also associated with additional serious ocular complications such as an increased incidence of refractive errors, amblyopia, strabismus, cataracts and glaucoma. ${ }^{2}$ Screening and early intervention are essential to reduce the complications of ROP.

ROP has been identified by the World Health Organization as a priority eye disease in the Vision 2020 statement for the global initiative for the elimination of avoidable blindness. ${ }^{3}$ The prevalence of ROP is strongly influenced by the level of socio-economic development of a specific region. In low-income countries with an infant mortality rate (IMR) over 60/1 000, the babies at highest risk of ROP do not survive and these countries therefore have a relatively low incidence of the disease. In countries with a low IMR $(<9 / 1000)$, more babies at the borders of viability survive and the ROP incidence is therefore high, but because of extensive screening programmes the associated complication rate is low. ${ }^{4}$ South Africa (SA) is classified as a middle-income country and has an IMR of $42.7 / 1000 .{ }^{5}$ This results in more babies surviving, but with a higher risk of developing ROP and its complications. Owing to financial constraints, physiological monitoring of sick infants is not optimal and the capacity for comprehensive screening programmes does not exist.
The most recent study on the incidence of ROP at our institution, Tygerberg Children's Hospital (TCH), Parow, Cape Town, was undertaken in 1995. Among infants ventilated for respiratory distress syndrome (RDS), the prevalence of ROP was $31.1 \%$ and that of clinically significant ROP (CSROP) 7.1\%. ${ }^{6}$ In the present study we differentiate CSROP (ROP of any grade in an area of the retina that might threaten sight) from 'any ROP', as the clinical implications differ.

Since 1995, protocols for treating infants with RDS have changed significantly. Surfactant has been introduced and use of non-invasive ventilation techniques has increased.

We aimed to determine the current prevalence of ROP at $\mathrm{TCH}$ in a cohort of preterm infants treated exclusively with non-invasive ventilation in the first week of life. Our second aim was to identify statistically significant risk factors for the development of ROP.

\section{Methods}

This study was a retrospective review of medical records of infants screened for ROP from January 2009 to December 2010.

\section{Ethics}

Ethical approval was obtained from the Stellenbosch University Ethics Committee (N11-03-082). 


\section{Inclusion criteria}

Inclusion criteria were: (i) infants of $\leq 28$ weeks' gestational age (GA) or $\leq 1000 \mathrm{~g}$ birth weight (BW) (where there was a discrepancy, the lower value of either BW or GA was used); and (ii) premature infants $>28$ weeks' GA or $>1000 \mathrm{~g}$ who had an exceptionally unstable course as per the discretion of the consultant.

\section{Exclusion criteria}

Exclusion criteria were: (i) invasive mechanical ventilation in the first week of life; (ii) major congenital abnormalities; and (iii) $\mathrm{BW}<500 \mathrm{~g}$

\section{Medical management}

In premature babies with any respiratory distress, continuous positive airway pressure ventilation (CPAP) was initiated immediately after birth by Neopuff ${ }^{\mathrm{TM}}$, followed by nasal CPAP after arrival in the ward. A positive end-expiratory pressure (PEEP) of $4-5 \mathrm{~cm} \mathrm{H}_{2} \mathrm{O}$ was used. Intubation, surfactant administration, then extubation (INSURE) was administered to infants with RDS (requiring a fraction of inspired oxygen $\left(\mathrm{FiO}_{2}\right) \geq 0.35$ to maintain saturations between $86 \%$ and $92 \%$ after 1 - 4 hours after birth).

Failure of CPAP and indications for mechanical ventilation were defined as: (i) recurrent apnoea despite CPAP with adequate seal and PEEP; (ii) severe rib retraction, sternal recession or grunting indicative of unsustainable increased work of breathing; and (iii) oxygenation or ventilation failure, as defined by pulse oximetry saturations $<90 \%$ or arterial oxygen level $\left(\mathrm{PaO}_{2}\right)<7 \mathrm{kPa}$ on $\mathrm{FiO}_{2} \geq 0.6$, arterial carbon dioxide level $\left(\mathrm{PaCO}_{2}\right)$ $>7.5 \mathrm{kPa}$ and $\mathrm{pH}<7.25$ (or base excess $>-10$ ), or an alveolar-arterial ratio of oxygen $<0.22$.

Criteria for weaning off oxygen to minimise the risk of developing ROP were as follows: (i) 33 - 36 weeks' corrected GA (or $\geq 1500 \mathrm{~g}$ ): maintain saturations at 88 - 92\%; and (ii) $\leq 32$ weeks' corrected GA (or $<1500 \mathrm{~g}$ ): maintain saturations at $86-90 \%$ (where there was a discrepancy, the lower value of either BW or GA was used).

Examination and staging of infants were done according to the International Classification of Retinopathy of Prematurity (2005 revision $)^{7}$ by a paediatric ophthalmologist using a 28-dioptre condensing lens and an indirect ophthalmoscope. A scleral depressor was used to rotate the globe in order to view the peripheral retina. Babies were examined

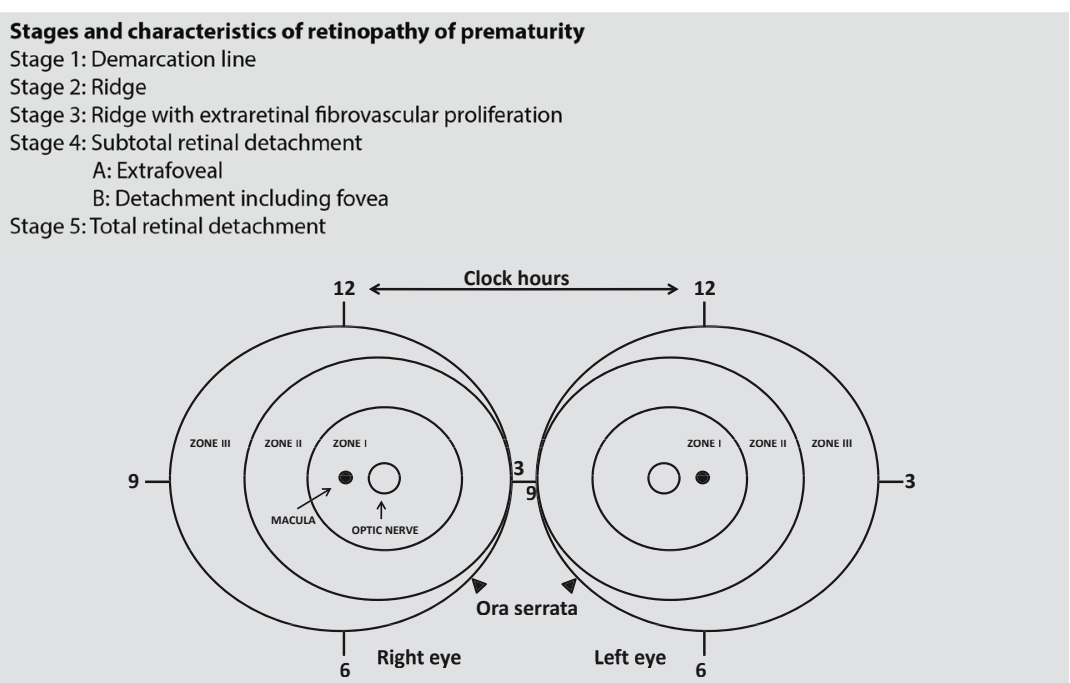

Fig. 1. ROP stages (International Committee for the Classification of Retinopathy of Prematurity classification) and zones.

from 31 weeks' corrected GA and then 1 - 3 times weekly until vascularisation of zone 3 was completed or the corrected GA of 41 weeks was reached. Babies who were not brought back for ROP screening were recorded as lost to follow-up.

CSROP was defined as ROP involving zone 1 , any stage 3 ROP, two or more quadrants of plus disease or worse surrounding the optic disc, or two or more quadrants of peripheral plus disease. Fig. 1 illustrates stages and zones, and Fig. 2 is an example of plus disease, showing a significant level of vascular dilation and tortuosity involving the posterior retinal vessels. Several risk factors have previously been found to be associated with development of ROP. The factors that we studied and their clarification are set out in Table 1.

\section{Statistics}

The clinical characteristics of the infants were described as either mean values with standard deviations (SDs), or rates and percentages. These characteristics were also described within weight subgroups. Two outcome measures were used, namely the presence or absence of any ROP and the presence or absence of CSROP. In order to determine which factors were associated with the outcome measures, univariate logistic regression analysis was performed to determine an association between the outcome measures and both continuous and categorical risk factors. Unadjusted odds ratios and 95\% confidence intervals were also determined for each effect. A $p$-value of $<0.05$ was considered statistically significant. Variables found to be significant in the univariate analysis, as well as variables with known clinical relevance, were included as factors in a multivariate logistic

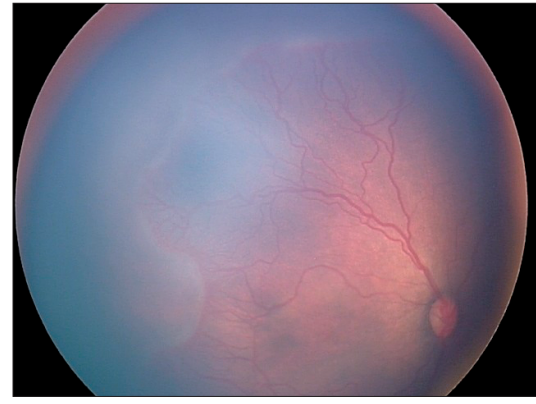

Fig. 2. Plus disease (a significant level of vascular dilation and tortuosity observed at the posterior retinal vessels).

regression (MLR). The MLRs were performed for each outcome in order to determine the possible association between the previously defined outcomes and the aforementioned variables. An adjustment was made for possible confounding of other factors.

\section{Results} were included in the study (Fig. 3). The population characteristics are shown in Table 2. The mean GA was 28.3 (SD \pm 1.7 ) weeks and the mean birth weight $949.3 \mathrm{~g}$. Two hundred and twenty-nine infants weighed $<1000 \mathrm{~g}$ and 172 weighed $\geq 1000 \mathrm{~g}$. Only 1 infant who qualified for screening as per consultant discretion weighed $\geq 1500 \mathrm{~g}$ - this baby weighed $1560 \mathrm{~g}$ at 30 weeks' GA and had a 36-day stay in the neonatal intensive care unit.

The prevalence of ROP (any ROP) was $75 / 356(21.8 \%)$ and that of CSROP $15 / 356$ (4.4\%) (Table 3). There was no CSROP in the group that weighed more than $1250 \mathrm{~g}$ at birth. Most ROP (75\%) occurred in the weight category less than $1000 \mathrm{~g}$. Univariate
Of the 395 babies screened for ROP, 356 
analysis of CSROP versus all babies without CSROP (Table 4) showed that the babies with CSROP were also significantly less mature (27.3 v. 28.3 weeks' GA) and smaller ( $851 \mathrm{~g} \mathrm{v} .949 \mathrm{~g}$ ). A significantly greater number of babies with CSROP had severe apnoea (66.7\% v. 26.5\%) and hyperglycaemia $(73.3 \%$ v. $44.2 \%)$, and received TPN $(46.7 \% \mathrm{v}$. 13.1\%). Babies with CSROP had worse weight gain than infants who were not diagnosed with CSROP (53.3\% v. $26.2 \%)$. HIV exposure was not associated with an increased prevalence of ROP.

MLR analysis revealed that lower birth weight and severe apnoea were the only statistically significant risk factors associated with the development of ROP (Table 5). Female gender showed a trend $(p=0.07)$ towards having a higher prevalence of ROP. MLR analysis of CSROP versus no ROP and insignificant ROP was statistically not possible owing to the small numbers in the CSROP group.

Laser therapy was performed in 6 infants (1.5\%). ROP screening was completed in $86.2 \%$. The lost-to-follow-up rate was therefore $13.8 \%$.

\section{Discussion}

TCH is a tertiary hospital undertaking 6000 complicated deliveries per year, drawn from the referral area in which there are 50000 deliveries per year.

The prevalence of ROP (21.8\%) and CSROP (4.4\%) among infants treated with non-invasive ventilation is low when compared with the results of Gilbert et al. ${ }^{8}$ It must be noted that these authors included ventilated babies, who are known to be at higher risk of developing ROP.

Varughese et al. found rates of ROP needing treatment of $1.6-2.9 \%{ }^{1}$ They used a convenience sample that included 17 units from three SA provinces. In line with their findings, a 2006 study from Chris Hani Baragwanath Hospital reported a 16.3\% incidence of ROP (adjusted estimation of CSROP 2.9\%), ${ }^{9}$ while researchers from Kalafong Hospital (2002) reported an incidence of ROP of 24.5\% (CSROP 4.3\%). ${ }^{10}$ The neonatal unit at Groote Schuur Hospital (1991) reported an incidence of ROP of 19.2\% (CSROP 1.56\%). ${ }^{11}$ The abovementioned studies all included infants weighing $<1500 \mathrm{~g}$.

\section{Table 1. Risk factors for ROP included in the study}

\begin{tabular}{|c|c|}
\hline Risk factor & Comments \\
\hline \multicolumn{2}{|l|}{ Advancing maternal age } \\
\hline $\begin{array}{l}\text { Maternal PET/PIH or chronic } \\
\text { hypertension }\end{array}$ & $\begin{array}{l}\text { Systolic } \mathrm{BP} \geq 140 \mathrm{mmHg} \text { or diastolic } \mathrm{BP} \geq 90 \mathrm{mmHg} \pm>0.3 \mathrm{~g} \text { protein in a } 24 \text {-hour urine specimen, noted in } \\
\text { pregnancy of }>20 \text { weeks' gestation }\end{array}$ \\
\hline Maternal DM & Gestational or other types of DM in pregnancy \\
\hline Antenatal steroids & Any type or dose of steroid \\
\hline \multicolumn{2}{|l|}{ HIV-exposed } \\
\hline \multicolumn{2}{|l|}{ Birth weight } \\
\hline Gestational age & $\begin{array}{l}\text { Calculated using one of the following: sure dates, early ultrasound ( } 24 \text { weeks was the cut-off for early } \\
\text { ultrasound examination), late ultrasound, or the postnatally determined Ballard score }{ }^{15}\end{array}$ \\
\hline \multicolumn{2}{|l|}{ Small for gestational age } \\
\hline \multicolumn{2}{|l|}{ Gender } \\
\hline \multicolumn{2}{|l|}{ Surfactant } \\
\hline \multicolumn{2}{|l|}{ Singleton v. multiple } \\
\hline Poor weight gain & $\begin{array}{l}\text { We used average gain per day. More than } 15 \mathrm{~g} \text { per day (not per } \mathrm{kg} \text { ) was considered adequate weight gain. We } \\
\text { excluded the first } 14 \text { days from the calculation in order to compensate for weight loss while feeds were being } \\
\text { established }\end{array}$ \\
\hline Hyperglycaemia & $\begin{array}{l}\text { A whole-blood glucose level was measured by Accu-Chek and hyperglycaemia diagnosed if }>8.5 \mathrm{mmol} / \mathrm{l} \text { on } \\
\text { two consecutive occasions (the monitoring is routinely done 3-hourly) }\end{array}$ \\
\hline Severe apnoea & $\begin{array}{l}\text { No spontaneous breathing }>20 \text { seconds, associated with desaturation or bradycardia requiring more } \\
\text { intervention than stimulation alone (temporary manual ventilation by Neopuff }{ }^{\mathrm{TM}} \text { or the addition of doxapram) }\end{array}$ \\
\hline Duration of $\mathrm{O}_{2}$ therapy & Days spent on NCPAP or nasal prong oxygen even if the blender was set at delivering an $\mathrm{FiO}_{2}$ of 0.21 \\
\hline Sepsis & Any positive culture from a normally sterile site \\
\hline Fungal infection & As diagnosed with positive blood culture \\
\hline NEC & Modified Bell's criteria stage $2^{16}$ or more \\
\hline $\mathrm{IVH} / \mathrm{PVH}$ & According to the Papile grading system \\
\hline Blood transfusion & All babies who received packed red blood cells, regardless of number of transfusions or volume of blood transfused \\
\hline PDA & $\begin{array}{l}\text { Diagnosed either by ultrasound or strong clinical suspicion and when the PDA was considered } \\
\text { haemodynamically significant enough to be treated with ibuprofen }\end{array}$ \\
\hline BPD & Supplemental oxygen dependent at 36-week PMA with chest X-ray changes typical of BPD \\
\hline Postnatal steroids & Any type of steroid for any duration and at any chronological age \\
\hline TPN & Any duration \\
\hline
\end{tabular}


On univariate analysis of 'no ROP' versus 'any ROP', the smaller, less mature babies, as well as those who developed sepsis, were at highest risk of developing ROP. In comparing CSROP with non-significant ROP on univariate analysis, the smaller, less mature babies and those with severe apnoea were worse affected.

That total parenteral nutrition (TPN) was associated with an increased prevalence of CSROP was unexpected. Good nutrition and growth has been shown to decrease the odds of developing ROP. ${ }^{12}$ However, counter-intuitive findings have been reported previously. ${ }^{13}$ We postulate that our findings might be biased due to the use of average weight gain over the entire admission period, as opposed to observing shorter periods of impaired growth. These factors may affect retinal development. We further postulate that the use of TPN may have selected out the babies with severe disease, because routine TPN is not offered at $\mathrm{TCH}$. We did not include duration of TPN, which may have been an indicator of severity of disease.

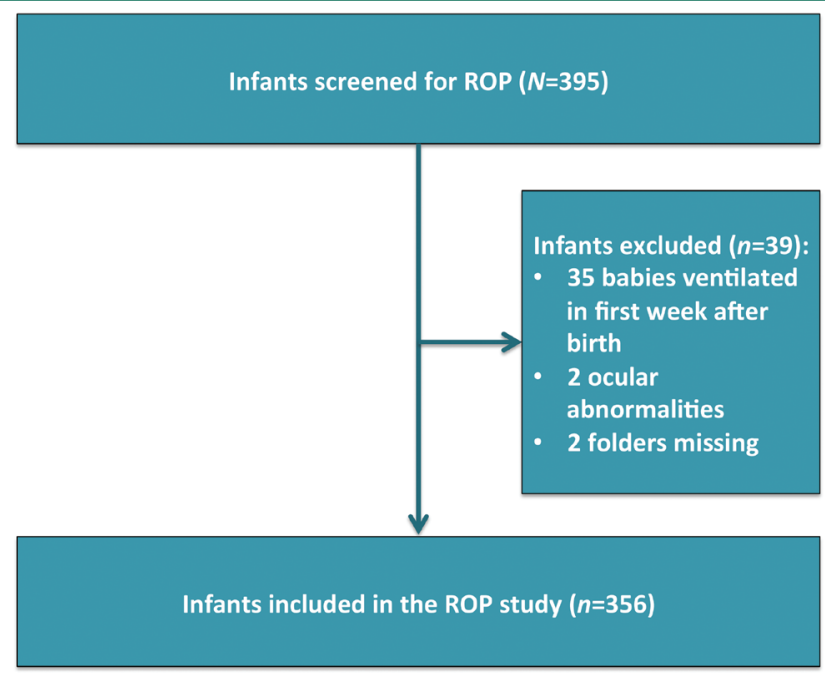

Fig. 3. Infants screened for ROP, and excluded from and included in the study.

Taking all confounding factors into consideration on MLR, an inverse relationship between birth weight and ROP existed. In this study 122 babies weighing $>1000 \mathrm{~g}$ were screened, of whom $19(5.5 \%)$ had ROP. Only two babies had CSROP, and they were in the group weighing 1000 - $1249 \mathrm{~g}$. No babies with a BW $\geq 1250 \mathrm{~g}$ had CSROP. Severe apnoea independently raised the risk for ROP, but this variable is not easy to define in clinical practice.

Postnatal weight gain, in addition to BW, has been shown to be important in the development of ROP. The WINROP algorithm $^{12}$ (conceptualised in Sweden), based on weekly weight gain, predicts the likelihood of a patient developing ROP. The first validation studies were published in 2009, and since then the algorithm has also been tested in developing countries such as Brazil.

\section{Strengths and limitations}

All infants were screened, or their screening supervised, by one ophthalmologist. Our lostto-follow-up rate was low compared with other SA studies (with the exception of the Chris Hani Baragwanath Hospital study). ${ }^{16,9,10}$ The exclusion of infants ventilated in the first week of life was a limitation. The inclusion of premature babies for ROP screening as per consultant discretion' is weakly defined and subjective.

Table 2. General population characteristics

\begin{tabular}{|c|c|c|c|c|c|}
\hline \multirow[b]{2}{*}{ Characteristic } & \multicolumn{4}{|c|}{ Birth weight (g) } & \multirow[b]{2}{*}{ Total } \\
\hline & $500-750$ & $751-1000$ & $1001-1250$ & $>1250$ & \\
\hline Number of infants, $n$ & 41 & 188 & 115 & 12 & 356 \\
\hline Birth weight $(\mathrm{g})$, median & 690 & 899 & 1084 & 1310 & 950 \\
\hline Gestational age (weeks), mean $( \pm \mathrm{SD})$ & $27.8( \pm 1.5)$ & $28.1( \pm 1.6)$ & $28.6( \pm 1.7)$ & $29.7( \pm 1.3)$ & $28.3( \pm 1.7)$ \\
\hline PDA, \% & 4.8 & 19.4 & 10.7 & 1.41 & 36.3 \\
\hline $\mathrm{BPD}, \%$ & 1.1 & 3.1 & 2.0 & 0.8 & 7.1 \\
\hline IVH/PVH grade $1+2, \%$ & 4.8 & 13.5 & 10.1 & 0.6 & 28.9 \\
\hline IVH/PVH grade $3+4, \%$ & 1.1 & 2.8 & 0.8 & 0.3 & 5.1 \\
\hline
\end{tabular}

Table 3. Prevalence of ROP

\begin{tabular}{|c|c|c|c|c|c|}
\hline & \multicolumn{4}{|c|}{ Birth weight (g) } & \multirow[b]{2}{*}{ Total } \\
\hline & $500-750$ & $751-1000$ & $1001-1250$ & $>1250$ & \\
\hline All ROP, $n(\%)$ & $11(3.2)$ & $45(13.1)$ & $18(5.2)$ & $1(0.3)$ & $75(21.8)$ \\
\hline CSROP, $n(\%)$ & $4(1.2)$ & $9(2.6)$ & $2(0.6)$ & 0 & $15(4.4)$ \\
\hline Not CSROP, $n(\%)$ & $7(2.0)$ & $36(10.5)$ & $16(4.6)$ & $1(0.3)$ & $60(17.4)$ \\
\hline No ROP, $n(\%)$ & $30(8.7)$ & $136(39.5)$ & $93(27.0)$ & $10(2.9)$ & $269(78.2)$ \\
\hline
\end{tabular}


Table 4. Univariate analysis (CSROP v. no ROP and insignificant ROP)

\begin{tabular}{|c|c|c|c|}
\hline Variable & CSROP & $\begin{array}{l}\text { No ROP plus } \\
\text { insignificant } \\
\text { ROP }\end{array}$ & $p$-value \\
\hline TPN, $n(\%)$ & $7(46.7)$ & $43(13.1)$ & 0.0003 \\
\hline Severe apnoea, $n(\%)$ & $10(66.7)$ & $87(26.5)$ & 0.0007 \\
\hline Gestational age, mean $( \pm S D)$ & $27.3( \pm 3.1)$ & $28.4( \pm 1.8)$ & 0.0209 \\
\hline Poor weight gain, $n$ (\%) & $8(53.3)$ & $86(26.2)$ & 0.0213 \\
\hline $\begin{array}{l}\text { Birth weight }(\mathrm{g}) \\
\text { mean }( \pm \mathrm{SD})\end{array}$ & $851( \pm 230.5)$ & $949.3( \pm 177.6)$ & 0.0233 \\
\hline Hyperglycaemia, $n$ (\%) & $11(73.3)$ & $145(44.2)$ & 0.0267 \\
\hline $\begin{array}{l}\text { Total oxygen time (days), } \\
\text { mean }( \pm \mathrm{SD})\end{array}$ & $25.7( \pm 34.2)$ & $16.3( \pm 20.9)$ & 0.0664 \\
\hline $\begin{array}{l}\text { NCPAP time (days), } \\
\text { mean }( \pm \mathrm{SD})\end{array}$ & $12.3( \pm 20.5)$ & $8.0( \pm 9.6)$ & 0.0770 \\
\hline $\begin{array}{l}\text { Any grade IVH/PVH, } \\
n(\%)\end{array}$ & $8(53.3)$ & $109(39.1)$ & 0.1069 \\
\hline Surfactant, $n(\%)$ & $7(50.0)$ & $110(33.5)$ & 0.2035 \\
\hline $\begin{array}{l}\text { Ventilation (days), } \\
\text { mean }( \pm \mathrm{SD})^{*}\end{array}$ & $2.7( \pm 11.4)$ & $1.0( \pm 5.9)$ & 0.2392 \\
\hline $\begin{array}{l}\text { Nasal prong oxygen duration } \\
\text { (days), mean }( \pm \text { SD })\end{array}$ & $10.7( \pm 15.4)$ & $7.3( \pm 12.2)$ & 0.2454 \\
\hline Singleton, $n(\%)$ & $11(73.3)$ & $277(84.2)$ & 0.2651 \\
\hline $\mathrm{BPD}, n(\%)$ & $0(0)$ & $24(7.0)$ & 0.2765 \\
\hline NEC, $n(\%)$ & $0(0)$ & $24(7.3)$ & 0.2773 \\
\hline Fungaemia, $n(\%)$ & $1(6.7)$ & $9(2.7)$ & 0.3755 \\
\hline $\begin{array}{l}\text { Maternal age (years), } \\
\text { mean }( \pm \mathrm{SD})\end{array}$ & $28.6( \pm 11.4)$ & $27.08( \pm 7.1)$ & 0.3838 \\
\hline Blood transfusion, $n(\%)$ & $11(73.3)$ & $209(63.5)$ & 0.4391 \\
\hline Sepsis, $n(\%)$ & $7(46.7)$ & $128(38.9)$ & 0.5472 \\
\hline Maternal DM, $n(\%)$ & $0(0)$ & $6(1.9)$ & 0.6051 \\
\hline $\begin{array}{l}\text { Small for gestational age, } \\
n(\%)\end{array}$ & $4(26.7)$ & $108(32.8)$ & 0.6185 \\
\hline Antenatal steroids, $n$ (\%) & $11(73.3)$ & $256(78.5)$ & 0.6332 \\
\hline HIV-exposed, $n$ (\%) & $2(13.3)$ & $56(17.1)$ & 0.7055 \\
\hline Gender (male), $n(\%)$ & $7(46.7)$ & $167(50.8)$ & 0.7565 \\
\hline PDA, $n(\%)$ & $6(40.0)$ & $121(36.9)$ & 0.8073 \\
\hline Postnatal steroids, $n$ (\%) & $1(6.7)$ & $26(7.9)$ & 0.8593 \\
\hline Maternal PIH/PET, $n(\%)$ & $7(50.0)$ & $161(50.3)$ & 0.9817 \\
\hline \multicolumn{4}{|c|}{ 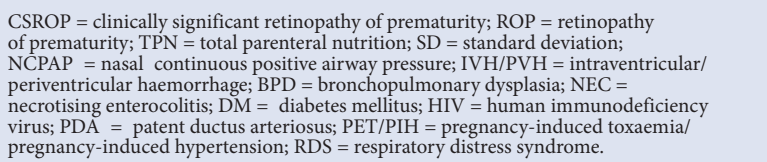 } \\
\hline
\end{tabular}

The reliability of GA estimation varies significantly, depending on how it was calculated. In this study the definitions of sepsis and fungaemia were very strict, and this may have masked the true influence of mild sepsis or fungaemia on ROP.

We did not assess the role of head growth in the development of stage $3 \mathrm{ROP}$ at the postmenstrual age of 31 weeks, ${ }^{14}$ because this measurement was inadequately recorded in our study population.
Table 5. Results of multivariate logistic regression analysis (no ROP v. any ROP)

\begin{tabular}{llll}
\hline Variable & $\boldsymbol{p}$-value & OR & CI \\
\hline Severe apnoea & 0.0005 & 2.67 & $1.54-4.63$ \\
Decreasing birth weight & 0.0382 & 1.002 & $1.00-1.004$ \\
Female gender & 0.0751 & 1.639 & $0.951-2.824$ \\
& & & \\
ROP = retinopathy of prematurity; OR = odds ratio; CI = confidence interval.
\end{tabular}

\section{Conclusion}

The prevalence of ROP and CSROP was low in this cohort of preterm infants treated exclusively with non-invasive ventilation in the first week of life, when compared with Gilbert et al.'s results. ${ }^{8}$

Screening for ROP is expensive, time-consuming and potentially harmful. SA public health services have limited capacity to adhere to the relatively liberal First-World inclusion criteria for screening.

BW is a practical and reproducible variable and can be used in ROP screening criteria. No infants in our study group who weighed more than $1250 \mathrm{~g}$ had CSROP. The implication is that, in selected units, this represents an acceptable upper limit beyond which screening is likely to be unnecessary.

Investigation of the applicability of the WINROP ${ }^{\circ}$ algorithm in SA is likely to be the next step towards determining effective ROP detection and screening strategies.

Acknowledgements. The authors thank the staff whose efforts made the screening programme possible, and the Department of Ophthalmology for providing funds to assist with data capturing.

\footnotetext{
References

1. Varughese S, Gilbert C, Pieper C, Cook C. Retinopathy of prematurity in South Africa: an assessment of needs, resources and requirements for screening programmes. Br J Ophthalmol 2008;92(7):879-882. http://dx.doi.org/10.1136/bjo.2008.137588]

2. Good WV, Hardy RJ, for the ETROP Multicenter Study Group. The multicenter study of early treatment for retinopathy of prematurity. Ophthalmology 2001;108(6):1013-1014.

3. Vision2020.org. The right to sight. Global initiative for the elimination of avoidable blindness. Action plan 2006-2011. http://www.vision2020.org/main.cfm (accessed 20 October 2011).

4. Gilbert C. Retinopathy of prematurity: A global perspective of the epidemics, population of babies at risk and implications for control. Early Hum Dev 2008;84(2):77-82. [http://dx.doi.org/10.1016/j. earlhumdev.2007.11.009]

5. CIA.gov. Central Intelligence Agency: The World Fact Book. https://www.cia.gov/library/publications/ the-world-factbook/fields/2091.html (updated 11 January 2011; accessed 18 January 2011).

6. Kirsten GF, Van Zyl JI, Le Grange M, Ancker E, Van Zyl F. The outcome at 12 months of very-lowbirth-weight infants ventilated at Tygerberg Hospital. S Afr Med J 1995;85(7):649-654

7. International Committee for the Classification of Retinopathy of Prematurity. The Internationa Classification of Retinopathy of Prematurity revisited. Arch Ophthalmol 2005;123(7):991-999. [http:// dx.doi.org/10.1001/archopht.123.7.991]

8. Gilbert C, Fielder A, Gordillo L, Quinn G, Semiglia R, Visintin P, Zin A; International NO-ROP Group Characteristics of infants with severe retinopathy of prematurity in countries with low, moderate, and high levels of development: implications for screening programs. Pediatrics 2005;115(5):e518-525. [http://dx.doi.org/10.1542/peds.2004-1180]

9. Mayet I, Cockinos C. Retinopathy of prematurity in South Africans at a tertiary hospital: a prospective study. Eye 2006;20(1):29-31. [http://dx.doi.org/10.1038/sj.eye.6701779]

. Delport SD, Swanepoel JC, Odendaal PJ, Roux P. Incidence of retinopathy of prematurity in very-lowbirth-weight infants born at Kalafong Hospital, Pretoria. S Afr Med J 2002;92(12):986-990.

1. Straker CA, Van der Elst CW. The incidence of retinopathy of prematurity at Groote Schuur Hospital, Cape Town. S Afr Med J 1991;80:287-288

12. Lofqvist C, Andersson E, Sigurdsson J, et al. Longitudinal postnatal weight and insulin-like growth factor 1 measurement in the prediction of retinopathy of prematurity. Arch Ophthalmol 2006;124:1711-1718. [http://dx.doi.org/10.1001/archopht.124.12.1711]

13. Bhandarkar SG, Salchow DJ, Chiang MF, Flynn JT, Le TC. Correlation between increased weight gain and onset of threshold retinopathy of prematurity. Invest Ophthalmol Vis Sci 2005;46:E-Abstract 4096 Lofqvist C, Engstrom E, Surgurdsson J, et al. Postnatal head growth deficit among premature infants parallels retinopathy of prematurity and insulin-like growth factor-1 deficit. Pediatrics 2006;117(9):1930. [http://dx.doi.org/10.1542/peds.2005-1926]

15. Ballard JL, Khoury JC, Wedig K, et al. New Ballard score, expanded to include extremely premature infants. J Pediatrics 1991;119:417-423.

16. Bell MJ, Ternberg JL, Feigin RD, et al. Neonatal necrotizing enterocolitis: Therapeutic decision based upon clinical staging. Ann Surg 1978:187:1-7.
}

Accepted 14 January 2013 